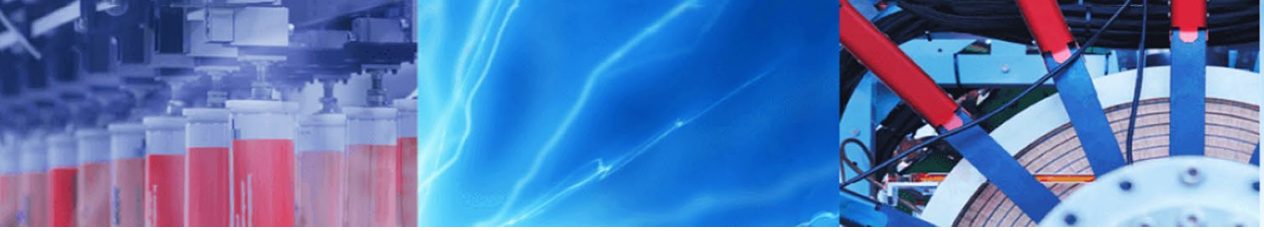

Research Article

\title{
Optimization of fuel properties of cottonseed biodiesel and its impact on engine performance and emission
}

\author{
Kshitij Puniyani ${ }^{1} \cdot$ Rohit Malik $^{1} \cdot$ Harshit Kumar ${ }^{1} \cdot$ Gaurav Dwivedi $^{2}$ (I)
}

(c) Springer Nature Switzerland AG 2019

\begin{abstract}
Rising level of pollution and extreme rate of depletion of fossil fuels has become a major issue in today's world which requires immediate measures for its prevention. Biodiesel is the potential answer to this threat to environment as being an extremely promising fuel given its adaptability of usage in currently existing engine modules. Out of various oil sources for biodiesel production (Jatropha, Pongamia, Neem, Mahua) Cotton seed oil is one of the prominent source for biodiesel production in India. The aim of this study to enhance the fuel quality of cotton seed biodiesel so that it can be used as an alternative fuel. Viscosity is an important indicator of progression of oxidation in biodiesel to be used in an engine. Viscosity and flash point of biodiesel is optimized with the help of anti-oxidant (pyrogallol) and by governing the adverse effects of oxidizing agent as metal contaminants of aluminium. The experimental investigation reveals that Cotton seed biodiesel $\left(\mathrm{CB}_{20}\right)$ with metal contamination there is decrease of $21.03 \%$ in brake thermal efficiency (BTE) and without metal contaminants there is decline of $11 \%$ was found as compared to diesel while brake specific fuel consumption (BSFC), was increased by $25.84 \%$ for $\mathrm{CB}_{20}$ with metal contaminants and for $\mathrm{CB}_{20}$ (without metal contaminants) there is increase in $10.73 \%$ as compared to diesel. There was a significant reduction in exhaust emissions including carbon monoxide (CO) and $\left(\mathrm{CO}_{2}\right)$ as for $\mathrm{CB}_{20}$ value reduction for $\mathrm{CO}_{2}$ was $41.35 \%$ and $38.27 \%$ for samples with and without metal contaminants. However, a $15.84 \%$ and $11.2 \%$ increase in oxides of nitrogen $\left(\mathrm{NO}_{x}\right)$ emission was experienced for biodiesel mixtures for $\mathrm{CB}_{20}$ with and without metal contaminants respectively as compared to diesel.
\end{abstract}

Keywords Biodiesel · Methyl esters · Metal contaminants · Emission · BSFC · BTE

\section{Abbreviations}

BSFC Brake specific fuel consumption

BTE Brake thermal efficiency

$\mathrm{NO}_{\mathrm{x}} \quad$ Nitrogen oxides

$\mathrm{CO}$ Carbon mono oxide

$\mathrm{CO}_{2}$ Carbon dioxide

$\mathrm{PY}$ Pyrogallol

Al Aluminium

$\mathrm{CB}_{\mathrm{x}} \quad$ Cottonseed biodiesel blend $\mathrm{BX}$

WC Without contaminant

C With contaminant

\section{Introduction}

Biodiesel is a fuel, which is a preliminary contender as an alternative fuel given the crisis of scarcity of fossil fuels and significant increase in pollution. Biodiesel being a carbon zero fuel becomes an exclusive choice as an alternative of fossil fuels. With the extra amount of oxygen, available biodiesel produces less carbon monoxide compared to diesel. Despite all the benefits oxidation stability of biodiesel is a major concern, which induces polymerized esters, resulting in insoluble gums and sediments causing fuel filter chocking [1]. Biodiesel comprises mainly of unsaturated fatty mono-alkyl esters, which is extracted by

Gaurav Dwivedi, gdiitr2005@gmail.com| 'School of Mechanical Engineering, VIT University, Vellore, India. ${ }^{2}$ Energy Centre, Maulana Azad National Institute of Technology, Bhopal 462 003, India.

SN Applied Sciences (2019) 1:1316 | https://doi.org/10.1007/s42452-019-1348-9

Received: 12 May 2019 / Accepted: 24 September 2019 / Published online: 1 October 2019 
the transesterification of vegetable oils or animal fats with simple alcohols, such as methanol, ethanol etc. [2, 3].

Biodiesel compounds contain esters having long oleic, linoleic or linolenic acid chains. These fatty acids have a tendency to oxidize and form long chains of polymers. The rate of oxidation depends on the number and position of double bonds. Polymerization of fatty acids forms series of by-products like acids, esters, aldehydes, ketones, etc. which leads to increase in viscosity and change in physical and chemical properties of the biodiesel [4]. Viscosity is an important indicator of progression of oxidation in biodiesel to be used in an engine [5-7].

Jain and Sharma [8] in their work studied the effect of various metals on interaction with Jatropha biodiesel and results concluded $\mathrm{Cu}$ as the strongest catalyzing agent for the oxidization of biodiesel to occur whereas Fe was found mostly inert towards the oxidation of biodiesel.

The addition of antioxidants was found beneficial for the stability of biodiesel and no negative impact was found on the physical properties [9-11]. Antioxidants enhance the oxidation stability of biodiesel, which helps to bring the properties within ASTM 6751, EN 14214 and IS 15607 standards [5]. Synthetically produced antioxidants are helpful in improving the oxidation stability of the biodiesel. Effect of antioxidant increases as its concentration increases, but oxidation of biodiesel cannot be negated completely [12-14]. Avase et al. [15] studied the effect of Pyrogallol (PY) on performance and emission characteristics of biodiesel and results showed that pyrogallol enhanced the blend properties and has narrowed the gap between the properties of blend and that of diesel. Ramalingam et al. [16] found out that antioxidants reduce the hydrogen free radicals in biodiesel which tends to reduce the $\mathrm{NO}_{\mathrm{x}}$ emissions which is also a major problem with the use of biodiesel. Celik et al. [17] investigated the impact of magnesium additive based rape seed methyl ester on engine emission result shows that there is result in reduction of $\mathrm{CO}, \mathrm{THC}$ and smoke emission while increase in $\mathrm{NO}_{x}$ emission.

Celik et al. [18] used organic based manganese fuel additive for engine operation which results in increase in maximum power output by $12.48 \%$ while the specific fuel consumption was reduced by $8.17 \%$.

Fazal et al. [19] investigated the effect of PY and butylated hydro-oxy toluene (BHT) on palm biodiesel properties when exposed to copper and mild steel metals. As a result, PY was found to be more effective than that of $\mathrm{BHT}$ in view of metal degradation suppression. Sarin et al. [20] in his work experimentally investigated that the impact of small concentrations of metal was mostly as same as larger concentrations. In addition, copper was found to be showing most catalytic behaviour for oxidation of biodiesel. Akhabue et al. [21] compares Fe and Al over the stability of castor oil methyl ester, Experimental study shows Fe provided better stability as compared to Al. With the rate of increase of metal contaminants, the rate of decomposition hydro peroxides was more than the rate of formation of hydro peroxides. Nabi et al. [22] in their study compared the brake thermal efficiency and brake specific fuel consumption of the different mixtures of cottonseed biodiesel and concluded that the brake thermal efficiency for biodiesel mixtures was relatively lesser than neat diesel. Also comparison has been done on the basis of emission from which conclusions drawn are minimal concentrations of $\mathrm{PM}$ and $\mathrm{CO}$ whereas the $\mathrm{NO}_{\mathrm{x}}$ emission is higher than neat diesel.

Aydin et al. [23] studied the performance and emission characteristics and compared the cottonseed biodiesel mixtures with diesel. It was concluded that with the increase in biodiesel in blends the concentration of the exhaust emissions decreased. Also no significant difference in efficiency was observed in low biodiesel blends but with the increase of content of biodiesel in blends, the performance was observed to be lower as compared to diesel. Fan et al. [24] found out that the fuel consumption rate of COME was higher than diesel and $\mathrm{CO}, \mathrm{CO}_{2}$ and $\mathrm{NO}_{\mathrm{x}}$ emissions were lower than diesel. Rakopoulos et al. [25] in their study investigated the performance and emissions of blends of B10 and B20 with the bus diesel engine at multiple speeds and loads. Investigation results concluded decrease in smoke intensity and $\mathrm{CO}$ concentration and increase in $\mathrm{NO}_{\mathrm{x}}$ and $\mathrm{HC}$ as compared to neat diesel. Yücesu et al. [26] in their paper studied the effects of cotton seed oil methyl ester on engine performance and emissions and concluded that performance of engine reduced by 3-9\% and specific fuel consumption was increased by $8-10 \%$. The study also concluded that the emissions of $\mathrm{CO}, \mathrm{CO}_{2}$ and $\mathrm{NO}_{\mathrm{x}}$ were found to be lower than diesel. Kumar et al. [27] found out that for cotton seed biodiesel carbon monoxide (CO), particulate matter (PM) and smoke emissions were less whereas $\mathrm{NO}_{x}$ was found to be slightly higher. Use of manganese additive in cotton methyl ester and evaluated the combustion and emission characteristics and the results shows that while using additives emissions like $\mathrm{CO}$, total hydrocarbon emission (THC) and smoke are reduced $[28,29]$.

Rashed et al. [30] in their study compared the effect of antioxidants in the blends of biodiesel on engine performance and emissions.

Hasni et al. [31] used response surface methodology to optimize the production parameters for the transesterification of Bruceajavanica seed oil and found out that on addition of antioxidant propylgallate, oxidative stability $(70 \mathrm{~h})$ is enhanced with a high efficiency. De Sousa et al. [32] found pyrogallol as the most favourable antioxidant. Balaji et al. [33] found out that anti-oxidant addition was 
effective for controlling the emissions and $\mathrm{HC}$ and $\mathrm{NO}_{\mathrm{x}}$ emissions were found to be decreased however $\mathrm{CO}$ and $\mathrm{CO}_{2}$ emissions increased due to disturbances in engine. Rashedul et al. [34] in their review study compared the effects additives in biodiesel on properties and performance of $\mathrm{Cl}$ engine.

Ramalingam et al. [16] in their review studied the effects of antioxidant additives with biodiesel with the engine performance and emission. Effect of antioxidant plays out effectively as it reduces the formation of $\mathrm{NO}_{x}$ by preventing the hydrogen free radicals. Antioxidant remained unaffected towards the engine performance but reduces $\mathrm{NO}_{x}$ emissions drastically.

Literature review states that very few studies were conducted on the fuel properties of cottonseed oil. In the present study, cottonseed biodiesel is undertaken and research has been performed in order to enhance the fuel properties and make it fit for the use. The present work aims to study the impact of antioxidant specifically pyrogallol on contaminated cottonseed oil using metal nanoparticles (aluminium). The work also provides an investigated study on engine performance using different cottonseed biodiesel blends.

\section{Materials and methods}

Methanol $\left(\mathrm{CH}_{4} \mathrm{O}\right)$ was obtained from Sisco research laboratories, Chennai, Tamil Nadu, India. Methanol obtained was $99 \%$ pure having boiling range of $64-65.5^{\circ} \mathrm{C}$. Potassium Hydroxide (KOH) having molecular weight of $56.11 \mathrm{~g} / \mathrm{mol}$ was also obtained from research laboratories, Chennai, Tamil Nadu, India. $\mathrm{KOH}$ bought had a purity of $85 \%$ and was stored at room temperature. Antioxidant pyrogallol $\left(\mathrm{C}_{6} \mathrm{H}_{6} \mathrm{O}_{3}\right)$ was also obtained from Sisco research laboratories, Chennai, Tamil Nadu, India. The sample obtained was $99 \%$ pure and had $\mathrm{pH}$ value between 4.0 and 5.0 and melting point was in between 132 and $134^{\circ} \mathrm{C}$. Aluminum nanoparticles molecular weight $26.98 \mathrm{~g} / \mathrm{mol}$ was obtained from BFC, Chennai, Tamil Nadu, India. Sample obtained was $98 \%$ pure. All chemicals used in the production are of AR grade.

\subsection{Biodiesel production}

The FFA content of cottonseed oil was very less (1.8\%), single stage acid based catalyzed transesterification process was used to prepare biodiesel. A measured volume of $800 \mathrm{~mL}$ cottonseed oil, methanol to cottonseed oil molar ratio of 9:1 and amount of catalysts was taken $4 \mathrm{wt} \%$. Once the reaction was completed, glycerin settles down at the bottom and biodiesel was in the upper phase. Biodiesel formed was washed once to separate any impurities of glycerin. The yield of the result was found to be $93 \%$. The biodiesel thus formed was tested for physiochemical properties as per ASTM D- 6751 standards and the values were compared with that of diesel in the Table 1 [18].

Experimental results in Table 1 shows that the viscosity of cottonseed biodiesel at the zeroth day was comparatively higher than diesel and from the literature it was found that with the increase in time the viscosity increases for which antioxidant was added to the mixture to inhibit the further oxidation hence preventing increase in viscosity. Considering the storage in a metal container, from the literature it was found that metal has a catalyzing effect and to analyze the effect metal nanoparticles were added in the mixture. Flash point of $C_{100}$ is found to be $101 \%$ higher than that of diesel whereas fire point was found to be $82 \%$ higher than that of Diesel. The experimental data were validated with the results by Krishna and Mallikarjuna [35].

\subsection{Methodology}

Crude cottonseed oil was undergone transesterification and converted into neat biodiesel. To study the effects of time, aluminum concentration and antioxidant (PY) concentration on viscosity, response surface methodology (RSM), Box-Behnken design was used to find the number of experiments to be performed. The data obtained from the experiments was analyzed using Design Expert 11. The solution found from the regression equation for optimized parameters was validated experimentally. Furthermore the optimized fuel was tested in a compression ignition engine for its engine performance and emission characteristics and compared with neat diesel.

\subsection{Sample preparation}

The three variables that were considered while performing the experiment which mainly influence the fuel

Table 1 Compares the physiochemical properties of $\mathrm{CB}_{100}$ and diesel

\begin{tabular}{lllll}
\hline S. no. & Properties & Units & $\mathrm{CB}_{100}$ & Diesel \\
\hline 1. & Flash point & ${ }^{\circ} \mathrm{C}$ & 117 & 58 \\
2. & Fire point & ${ }^{\circ} \mathrm{C}$ & 135 & 74 \\
3. & Density & $\mathrm{kg} / \mathrm{m}^{3}$ & 941 & 834 \\
4. & Kinematic viscosity & Centistoke & 5.31 & 3.54 \\
5. & Dynamic viscosity & Centipoise & 4.99 & 2.93 \\
6. & Calorific value & $\mathrm{MJ} / \mathrm{kg}$ & 41.8 & 45.5 \\
7. & Cetane number & & 47 & 51 \\
8. & Cloud point & ${ }^{\circ} \mathrm{C}$ & 9 & 5 \\
9. & Pour point & ${ }^{\circ} \mathrm{C}$ & 7 & 3 \\
\hline
\end{tabular}


properties of biodiesel were time, antioxidant concentration and metal contaminants concentration. To identify the number of samples, RSM was used. Design Expert 11, Box-Behnken design was used with three variables (stated above) and two responses (experimental viscosity, predicted viscosity).

Metal contaminant considered here is aluminium nanoparticles and antioxidant considered is pyrogallol (PY). Samples $(50 \mathrm{ml})$ of cottonseed biodiesel with the varying concentrations of metal from 0 to $100 \mathrm{ppm}$ and that of antioxidant from 0 to $1000 \mathrm{ppm}$ were prepared. Table 2 shows the experimental range of the factors for viscosity. These samples are then tested for viscosity and flash point. The results obtained are hence compared with the predicted results and optimized results are obtained. Finally, the samples with best results were considered and blends of $\mathrm{CB}_{10}, \mathrm{CB}_{20}$ and $\mathrm{CB}_{40}$ were made and the engine emission testing is performed for the blends.

Table 2 The experimental range of the factors for viscosity

\begin{tabular}{lll}
\hline Factors & Observations & Range \\
\hline Time & In range & $0-30$ \\
Metal concentration & In range & $0-100$ \\
Antioxidant concentration & In range & $0-1000$ \\
Viscosity & Minimum & - \\
\hline
\end{tabular}

\section{Results and discussion}

\subsection{Results}

Biodiesel storage parameters were optimized using RSM with Box-Behnken design. Optimal levels of the following parameters: time, antioxidant (PY) concentration and metal (Aluminium) concentration, were suggested by the solving the equation involved. A total of 17 experiments suggested by the Design-Expert 11 software were performed and viscosity and flash point were found for each sample prepared. Out of 17 experiments, there were 4 replicates and 13 individuals. The 13 individuals were the combinations of different levels of the above parameters. The effect of each parameter is determined from the obtained equation of viscosity and flash point. Experimental and predicted kinematic viscosity and flash point of samples formed with their antioxidants and metal contaminants variations has been shown in Tables 3 and 4 respectively.

Viscosity in terms of coded factors has been given below:

$$
\begin{aligned}
\text { viscosity }= & 6.26+1.26 * A+3.66 * B+2.01 * C \\
& +0.1375 * A B-0.0250 * A C+0.1275 * B C \\
& +2.37 * A^{2}+1.17 * B^{2}+2.41 * C^{2}
\end{aligned}
$$

Table 3 The number of samples formed their variations and the value of predicted and experimental kinematic viscosity

\begin{tabular}{llrrcc}
\hline Run & Time (days) & $\begin{array}{l}\text { Antioxidant } \\
(\mathrm{ppm})\end{array}$ & Metal (ppm) & $\begin{array}{l}\text { Viscosity (experimen- } \\
\text { tal) (centistoke) }\end{array}$ & $\begin{array}{l}\text { Viscosity (pre- } \\
\text { dicted) (cen- } \\
\text { tistoke) }\end{array}$ \\
\hline 1 & 15.5 & 500 & 50 & 6.35 & 6.25 \\
2 & 15.5 & 500 & 50 & 6.35 & 6.25 \\
3 & 15.5 & 500 & 50 & 6.32 & 6.25 \\
4 & 1 & 500 & 0 & 5.96 & 7.74 \\
5 & 1 & 0 & 50 & 5.05 & 5.01 \\
6 & 1 & 1000 & 50 & 12.19 & 12.07 \\
7 & 30 & 500 & 100 & 16.07 & 14.23 \\
8 & 15.5 & 0 & 0 & 6.04 & 4.27 \\
9 & 15.5 & 0 & 100 & 6.4 & 8.05 \\
10 & 30 & 1000 & 50 & 14.83 & 14.81 \\
11 & 30 & 500 & 0 & 8.7 & 10.26 \\
12 & 15.5 & 1000 & 100 & 13.89 & 7.21 \\
13 & 30 & 0 & 50 & 7.14 & 6.25 \\
14 & 15.5 & 500 & 50 & 6.12 & 6.25 \\
15 & 15.5 & 500 & 50 & 6.16 & 11.82 \\
16 & 1 & 500 & 100 & 13.43 & 11.35 \\
17 & 15.5 & 1000 & 0 & 13.02 & \\
\hline
\end{tabular}


Table 4 The number of samples formed their variations and the value of predicted and experimental flash point

\begin{tabular}{llrrll}
\hline Run & Time (days) & $\begin{array}{l}\text { Antioxidant } \\
(\mathrm{ppm})\end{array}$ & Metal $(\mathrm{ppm})$ & $\begin{array}{l}\text { Flash point (experi- } \\
\text { mental) }\left({ }^{\circ} \mathrm{C}\right)\end{array}$ & $\begin{array}{l}\text { Flash point } \\
\text { (predicted) } \\
\left({ }^{\circ} \mathrm{C}\right)\end{array}$ \\
\hline 1 & 15.5 & 500 & 50 & 112 & 112.8 \\
2 & 15.5 & 500 & 50 & 113 & 112.8 \\
3 & 15.5 & 500 & 50 & 111 & 112.8 \\
4 & 1 & 500 & 0 & 120 & 119.62 \\
5 & 1 & 0 & 50 & 121 & 119.38 \\
6 & 1 & 1000 & 50 & 132 & 133.12 \\
7 & 30 & 500 & 100 & 138 & 138.8 \\
8 & 15.5 & 0 & 0 & 117 & 119 \\
9 & 15.5 & 0 & 100 & 119 & 119.75 \\
10 & 30 & 1000 & 50 & 145 & 136.62 \\
11 & 30 & 500 & 0 & 134 & 134 \\
12 & 15.5 & 1000 & 100 & 136 & 136.88 \\
13 & 30 & 0 & 50 & 138 & 112.8 \\
14 & 15.5 & 500 & 50 & 111 & 112.8 \\
15 & 15.5 & 500 & 50 & 112 & 120.88 \\
16 & 1 & 500 & 100 & 120 & 128.25 \\
17 & 15.5 & 1000 & 0 & 129 & \\
\hline
\end{tabular}

Flash Point in terms of coded factors has been given below:

$$
\begin{aligned}
\text { flashpoint }= & 112.80+7.75 * A+5.88 * B+1.63 * C \\
& -1.00 * A B+1.00 * A C+1.25 * B C \\
& +11.97 * A^{2}+9.22 * B^{2}+3.23 * C^{2}
\end{aligned}
$$

\subsection{Analysis of variance and validation of method}

ANOVA results obtained are important to check the influence of the parameters affecting the viscosity and flash point. P-values for the model terms $B, C, A^{2}$ and $C^{2}$ are found to be less than 0.05 ; therefore they are significant for viscosity. P-values for the model terms $A, B, A^{2}, B^{2}$ and $C^{2}$ are found to be less than 0.05 ; therefore they are significant for flash point. Since no term linear or quadratic has $p$ value greater than 0.1 , so there is no insignificant term for viscosity. Since $A B, A C, B C$ have $p$ value greater than 0.1 , so they are insignificant terms for flash point. The F-value of the viscosity model (7.09) implies the model is significant. F-value this large could occur due to noise only have $0.85 \%$ chances. The F-value of the flash point model (43.77) implies the model is significant. F-value this large could occur due to noise only have $0.01 \%$ chances. The lack of fit F-value of 636.94 for viscosity implies the lack of fit is significant. There is only a $0.01 \%$ chance that a lack of fit F-value this large could occur due to noise. The lack of fit F-value of 1.69 for flash point implies the Lack of Fit is not significant relative to the pure error. There is only a $30.58 \%$ chance that a lack of fit F-value this large could occur due to noise. The $\mathrm{R}^{2}$ value is a measure of how well the regression approximates the real data points. In the present research, we obtained 0.9012 as $R^{2}$ for viscosity and 0.9825 as $R^{2}$ for flash point. Adequate Precision is a measure of the signal to noise ratio, which if greater than 4 is desirable. In this case it is 8.8 for viscosity and 20.14 for flash point indicating an adequate signal. Figure 1 shows the variation of predicted and actual values of the output response in terms of viscosity and flash point. Figure 2 shows the deviation of coded units from the reference points for viscosity and flash point.

\subsection{Discussions}

\subsubsection{Viscosity}

Figure 3 illustrates the variation of viscosity with respect to time, aluminium concentration and antioxidant concentration. Interaction of time (1-30 days), metal concentration (0-100 ppm) and antioxidant concentration (0-1000 ppm), taking two factors at a time while keeping the other one at its central value, has been interpreted in the graphs. Viscosity increases with increase in antioxidant concentration. With respect to aluminum metal concentration viscosity decreases a little then increases. Increase in viscosity with respect to increase in antioxidant concentration is found to be more profound as compared to increase in aluminum metal concentration which may be the result of reaction of antioxidant with the oxygen present in the solution and thus forming products which increases the viscosity. 

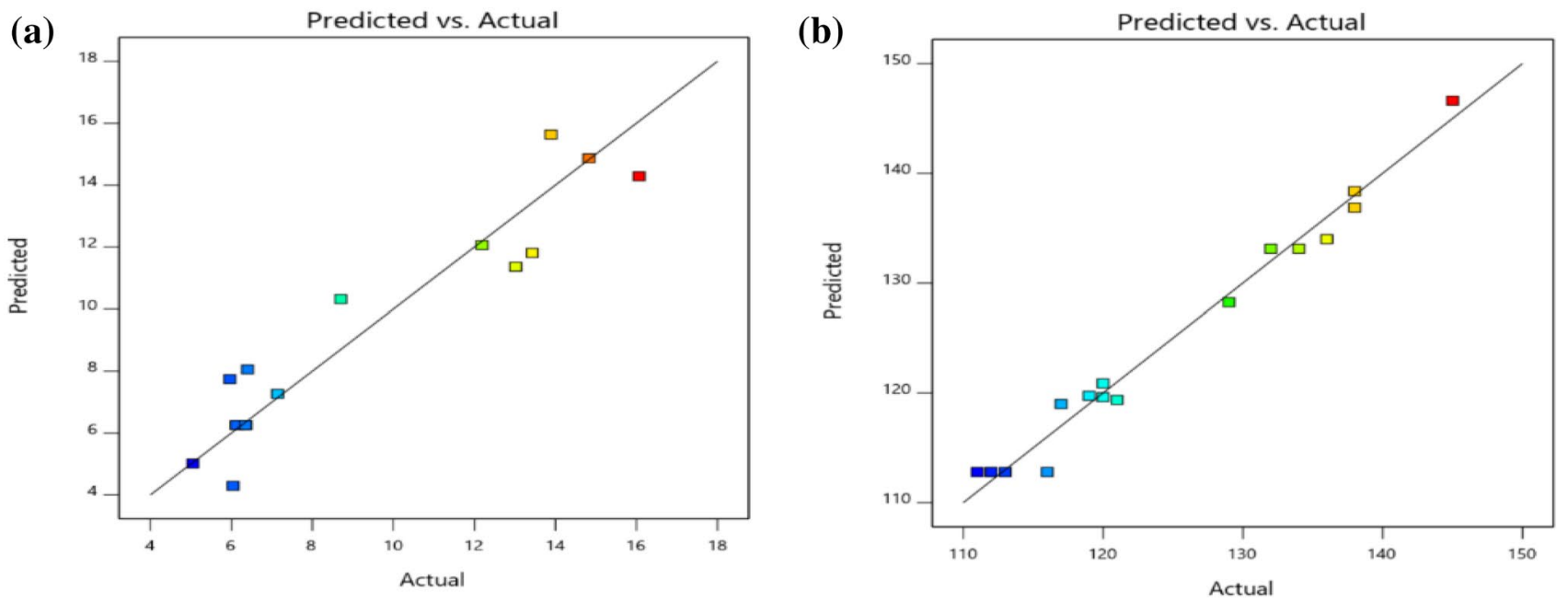

Fig. 1 Depicts the variation predicted versus actual values for $\mathbf{a}$ viscosity and $\mathbf{b}$ flash point respectively
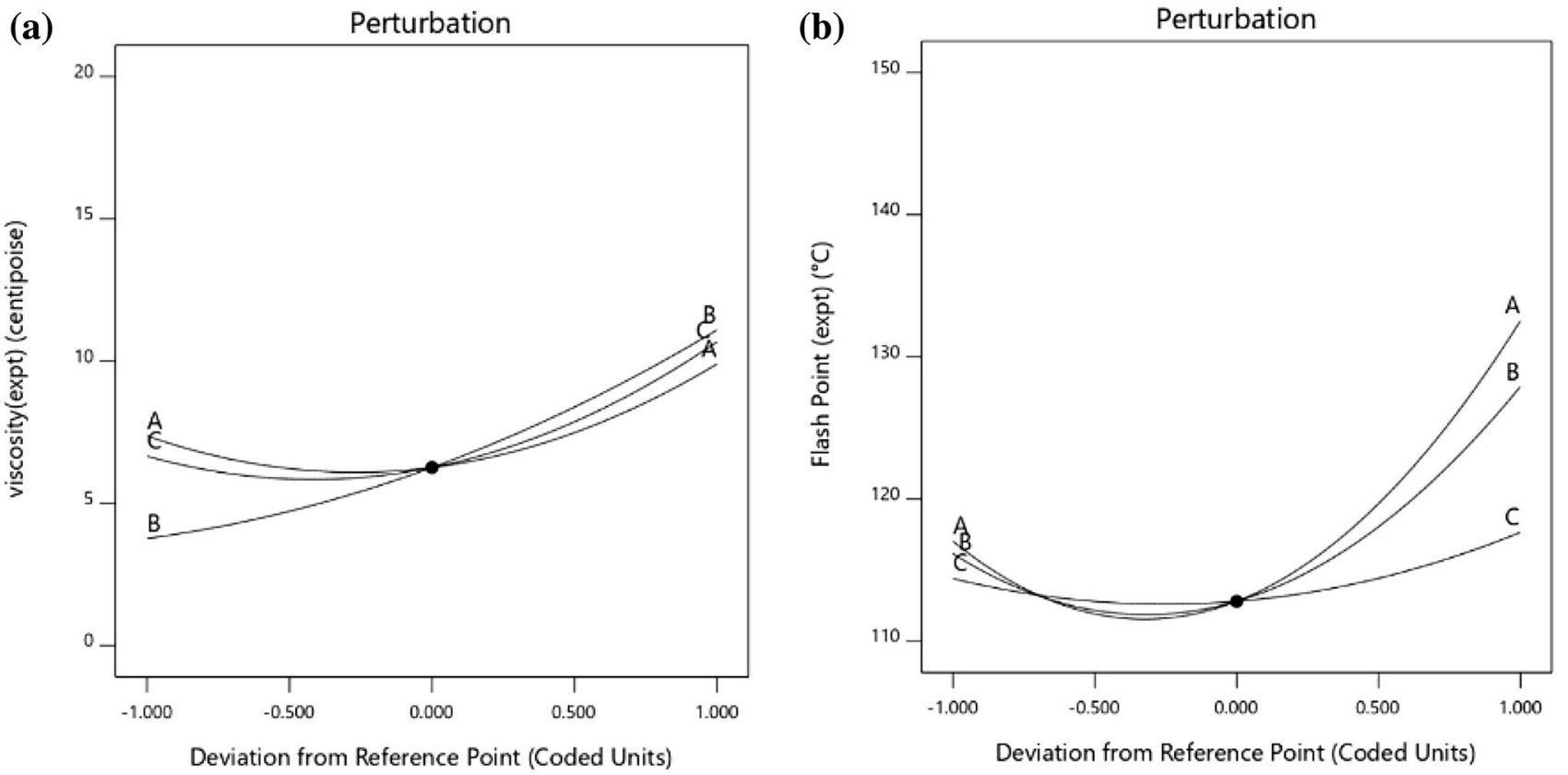

Fig. 2 Depict the deviation from reference points (coded units) versus a viscosity and $\mathbf{b}$ flash point

\subsubsection{Flash point}

Figure 4 illustrates the variation of flash point with respect to time, aluminium concentration and antioxidant concentration. Interaction of time (1-30 days), metal concentration (0-100 ppm) and antioxidant concentration (0-1000 ppm), taking two factors at a time while keeping the other one at its central value, has been interpreted in the graphs. All the three graphs are found to be of concave nature, thus indicating a minimum value for flash point. Flash point seems to decrease and then increase with respect to all the parameters in question. The experimentation validation of kinematic viscosity and flash point is shown in Tables 5 and 6 respectively. 

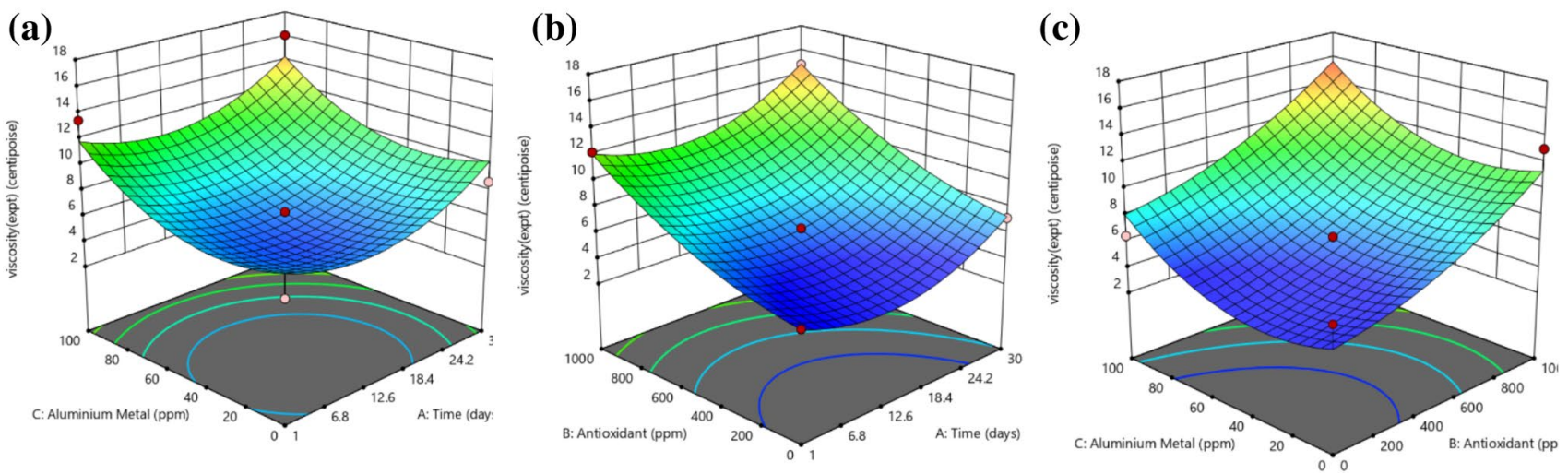

Fig. 3 Depict the variation of viscosity with respect to $\mathbf{a}$ time and aluminum concentration, $\mathbf{b}$ time and antioxidant concentration and $\mathbf{c}$ antioxidant and aluminum concentration respectively
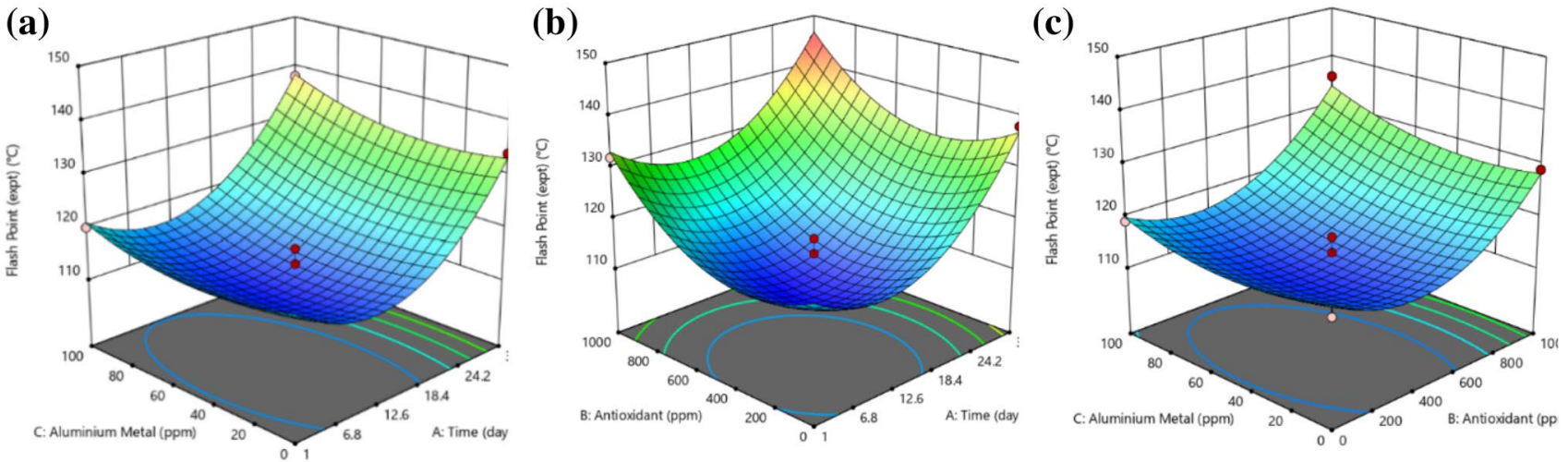

Fig. 4 Depict the variation of flash point with respect to $\mathbf{a}$ time and aluminum concentration, $\mathbf{b}$ time and antioxidant concentration and $\mathbf{c}$ antioxidant and aluminum concentration respectively

Table 5 The experimental validation of predicted values for viscosity

\begin{tabular}{lllll}
\hline & Time & Antioxidant & Aluminum & Viscosity \\
\hline Units & Days & $\mathrm{ppm}$ & $\mathrm{ppm}$ & Centistokes \\
Predicted value & 22.54 & 89.273 & 35.543 & 4.813 \\
$\begin{array}{l}\text { Experiment valida- } \\
\quad \text { tion }\end{array}$ & 23 & 90 & 35 & 5.34 \\
Error (\%) & 2.04 & 3.05 & 1.52 & 12.59 \\
\hline
\end{tabular}

Table 6 The experimental validation of predicted values for flash point

\begin{tabular}{lllll}
\hline & Time & Antioxidant & Aluminum & Flash point \\
\hline Units & Days & $\mathrm{ppm}$ & $\mathrm{ppm}$ & ${ }^{\circ} \mathrm{C}$ \\
Predicted value & 22.54 & 89.273 & 35.543 & 121.14 \\
$\begin{array}{l}\text { Experiment valida- } \\
\quad \text { tion }\end{array}$ & 23 & 90 & 35 & 128 \\
Error (\%) & 2.04 & 3.05 & 1.52 & 5.56 \\
\hline
\end{tabular}

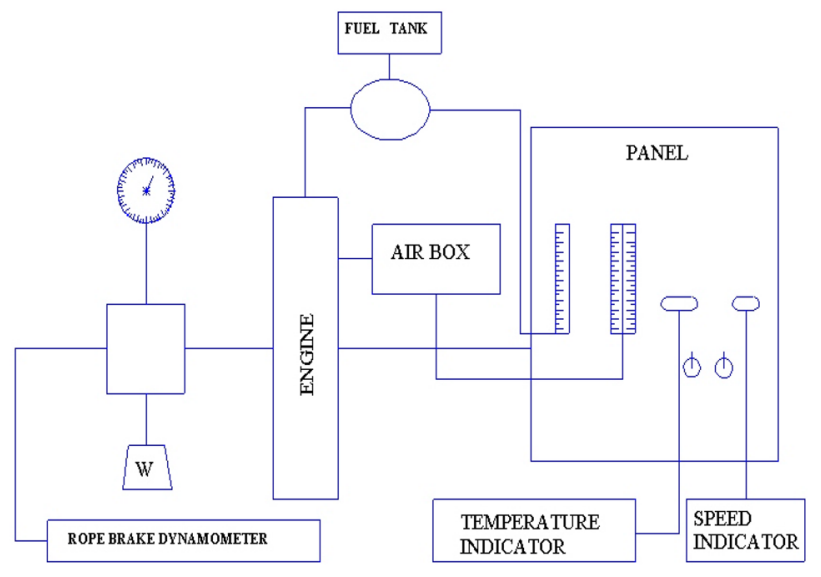

Fig. 5 Engine schematic dig 
Table 7 The properties of blends

\begin{tabular}{lllllll}
\hline Properties & Units & Diesel & $\mathrm{CB}_{10}$ & $\mathrm{CB}_{20}$ & $\mathrm{CB}_{40}$ & $\mathrm{CB}_{100}$ \\
\hline Density & $\mathrm{kg} / \mathrm{m}^{3}$ & 834 & 838 & 853 & 867 & 941 \\
Flash point & ${ }^{\circ} \mathrm{C}$ & 58 & 69 & 76 & 88 & 117 \\
Fire point $\left({ }^{\circ} \mathrm{C}\right)$ & ${ }^{\circ} \mathrm{C}$ & 74 & 87 & 93 & 104 & 135 \\
$\begin{array}{l}\text { Kinematic viscosity } \\
\left(40^{\circ} \mathrm{C}\right)\end{array}$ & Centistokes & 3.54 & 3.72 & 3.903 & 4.27 & 5.31 \\
\hline
\end{tabular}

Table 8 The engine specification

\begin{tabular}{ll}
\hline Speed & $1500 \mathrm{rpm}$ \\
\hline Model & AV1 \\
Cycle & 4 stroke \\
Rated power & $3.7 \mathrm{~kW}(5 \mathrm{BHP})$ \\
Cooling system & Water cooling \\
lgnition System & Compression ignition \\
\hline
\end{tabular}

Table 9 The dynamometer specifications

\begin{tabular}{ll}
\hline Make & Tachometer \\
\hline Diameter of the rope & $0.01 \mathrm{~m}$ \\
Diameter of the brake drum & $0.2 \mathrm{~m}$ \\
Controller & Manual based \\
\hline
\end{tabular}

\section{Engine performance and emission characteristics}

Engine performance and emission characteristics of three different blends of cottonseed biodiesel were performed with and without metal contaminants and the results were analyzed to draw a conclusion. Figure 5 represents the engine schematic diagram.

\subsection{Blend properties and properties}

Blends of cottonseed biodiesel are taken as $\mathrm{CB}_{10}, \mathrm{CB}_{20}$, $\mathrm{CB}_{40}, \mathrm{CB}_{100}$ and neat Diesel for the experiments of engine performance and engine emission. Upon comparing the values shown in Table 7, of diesel and $\mathrm{CB}_{100}$ it was observed the density of $\mathrm{CB}_{100}$ was $11.37 \%$ higher than diesel.

Also on comparing other physical values it was observed that viscosity of CB100 was higher by $30.26 \%$ whereas on comparison with the calorific value. Hence, the blends were prepared as $\mathrm{CB}_{10}, \mathrm{CB}_{20}$ and $\mathrm{CB}_{40}$ since there was a significant change of cottonseed biodiesel as compared to neat diesel; hence it was not possible to do the test as it may cause damage to engine. The prepared blends, $\mathrm{CB}_{10}, \mathrm{CB}_{20}$ and $\mathrm{CB}_{40}$ had densities as $838 \mathrm{~kg} / \mathrm{m}^{3}$, $853 \mathrm{~kg} / \mathrm{m}^{3}$ and $867 \mathrm{~kg} / \mathrm{m}^{3}$ respectively also viscosities
Table 10 The error in the various factors

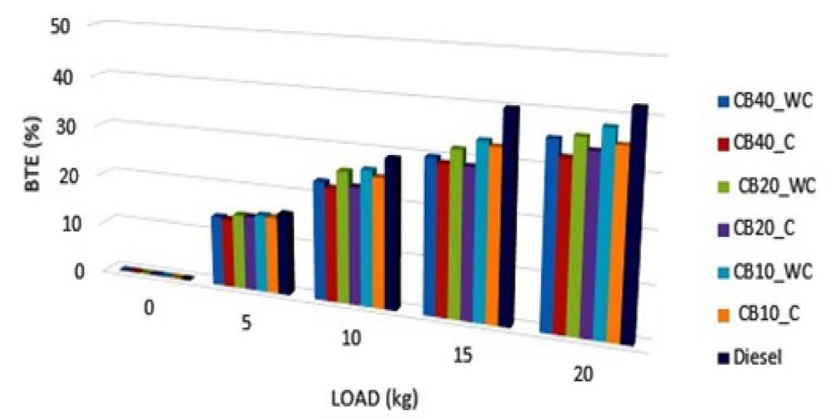

Fig. 6 The variation of brake thermal efficiency and load with neat diesel and various blends of biodiesel with and without contaminants

found were 4.62 centistokes, 4.903 centistokes, 5.31 centistokes respectively.

\subsection{Specification and error analysis}

The specifications of the engine and rope brake dynamometer used in the research are listed below in Tables 8 and 9:

\subsubsection{Error analysis}

Instrument selection, calibration, environmental conditions and human errors while recording the observations leads to errors. Uncertainty analysis is performed to analyse the accuracy of the experiments. The maximum errors in all the primary parameters are considered to evaluate the total error. Principle of propagation of errors was used to evaluate the total percentage uncertainty of an experimental trial. Factors contributing error has been listed in Table 10. 


\subsection{Engine performance}

\subsubsection{Brake thermal efficiency}

Figure 6 shows the variation of brake thermal efficiency and load with neat diesel and various blends of biodiesel with and without contaminants. Contaminants consist of aluminium in powdered form while the blends were added with the antioxidant which was pyrogallol.

Curve shows to be increasing with the increase in load and begins to decline from a certain point in load. Efficiency of neat diesel was found to be relatively higher than the bio-diesel blends also the better efficiency was found for blends without metal contaminants. Low efficiency of biodiesel blends can be governed to poor spray characteristics and low calorific value which remain inaffectant of antioxidant hence has no significant change as validated from Nabi et al. [22]. The variation in values observed for $10 \mathrm{~kg}$ load are stated as follows:

- Samples without contaminant had efficiency which $8.9 \%, 11 \%$ and $20 \%$ lower for $\mathrm{CB}_{10}, \mathrm{CB}_{20}$ and $\mathrm{CB}_{40}$ respectively and samples with contaminants had efficiency $13.10 \%, 21.03 \%$ and $23.4 \%$ lower for $\mathrm{CB}_{10}, \mathrm{CB}_{20}$ and $\mathrm{CB}_{40}$ respectively when compared to diesel.

- As evident from the data, the samples had efficiency less than diesel however metal contaminants had further negative impact on efficiency. Also, addition of antioxidant had a positive impact in the efficiency.

\subsubsection{Brake specific fuel consumption}

Experimental study shows that BSFC is inversely proportional to brake thermal efficiency hence contrary to the brake thermal efficiency the brake specific fuel consumption decreases with the increase in load and at a certain point contra-flexure is obtained indicating the decrease in declination of curve. BSFC value of neat diesel was found lower than the other blends of biodiesel and blends with

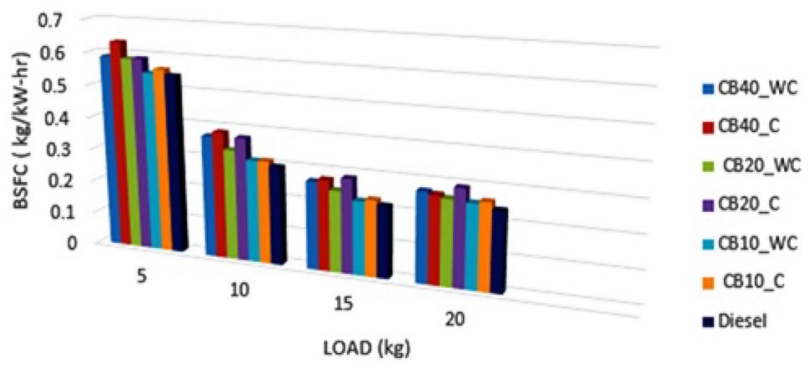

Fig. 7 The variation of brake specific fuel consumption and load with neat diesel and various blends of biodiesel with and without contaminants contaminants showed higher fuel consumption rate governing the high viscosity of the sample with contaminant as validated from Nabi et al. [22]. Figure 7 shows the variation of brake specific fuel consumption and load with neat diesel and various blends of biodiesel with and without contaminants.

The variation in values observed for $10 \mathrm{~kg}$ are stated as follows:

- Samples without contaminant had fuel consumption rate which was $4.02 \%, 10.73 \%, 24.49 \%$ higher for $\mathrm{CB}_{10}$, $\mathrm{CB}_{20}$ and $\mathrm{CB}_{40}$ respectively and samples with contaminants had fuel consumption rate which was $4.69 \%$, $25.83 \%$ and $29.53 \%$ higher for $\mathrm{CB}_{10}, \mathrm{CB}_{20}$ and $\mathrm{CB}_{40}$ respectively when compared to diesel.

- As evident from the above data as metal contaminants had a negative impact on efficiency, its fuel consumption rate was found significantly higher than with the samples having antioxidants. The entire biodiesel blend values specific fuel consumption rate was found to be higher than diesel by significant value.

\subsection{Emission characteristics}

\subsection{1 $\mathrm{NO}_{\mathrm{x}}$ emission}

An increasing curve trend was observed for $\mathrm{NO}_{x}$ as the $\mathrm{NO}_{x}$ value was increasing with the increase in load. $\mathrm{NO}_{\mathrm{x}}$ formation takes place in very high temperature. It is observed that the $\mathrm{NO}_{\mathrm{x}}$ emission was more in biodiesel as compared to diesel as it has high flash and fire point; however the use of additives reduced the $\mathrm{NO}_{\mathrm{x}}$ emissions as they inhibit the formation of free radicals [21]. Figure 8 illustrates the variation of $\mathrm{NO}_{x}$ emissions and the load with neat diesel and various blends of biodiesel with and without contaminants.

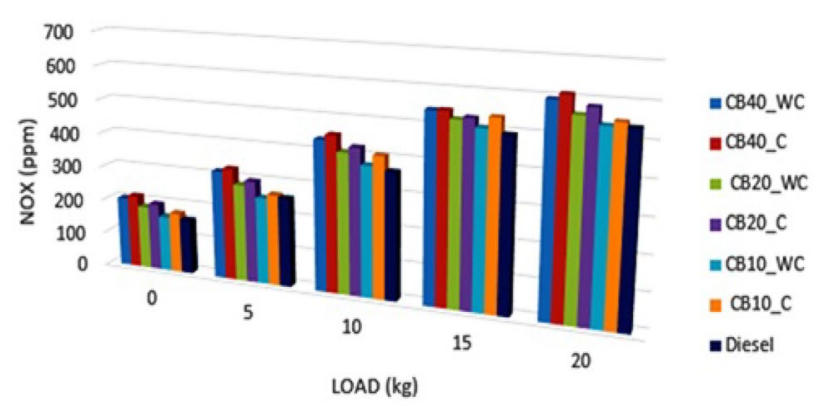

Fig. 8 Illustrates the variation of $\mathrm{NO}_{\mathrm{x}}$ emissions and the load with neat diesel and various blends of biodiesel with and without contaminants 


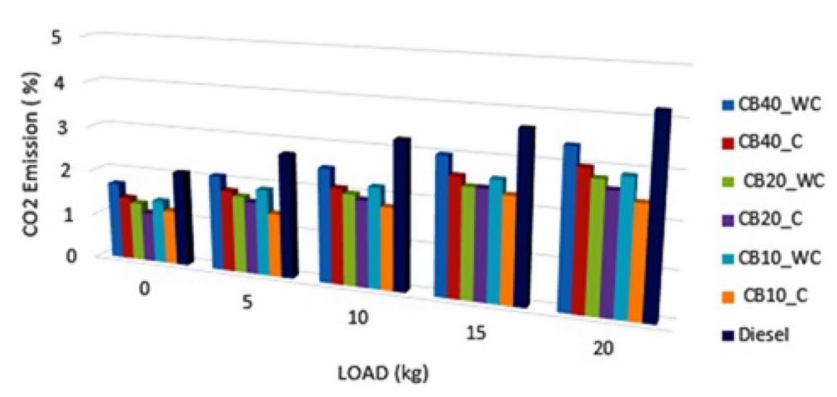

Fig. 9 Illustrate the variation of $\mathrm{CO}_{2}$ values as compared with the load applied

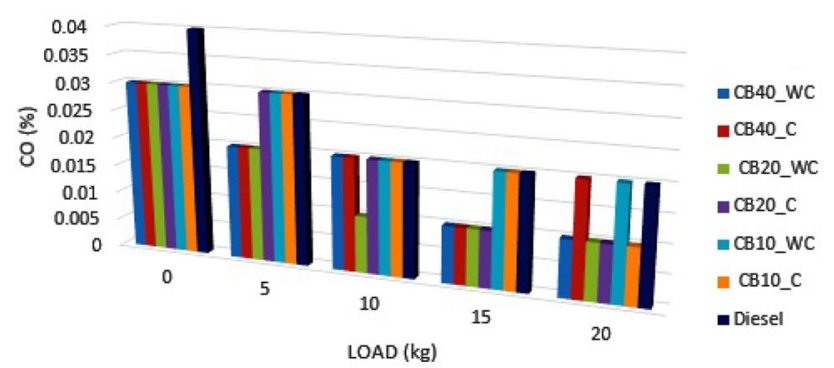

Fig. 10 Illustrate the variation of CO values as compared with the load applied

The variation in values observed for $10 \mathrm{~kg}$ are stated as follows:

- Samples without contaminant had $\mathrm{NO}_{\mathrm{x}}$ emission which was $3 \%, 11.2 \%, 19.39 \%$ higher for $\mathrm{CB}_{10}, \mathrm{CB}_{20}$ and $\mathrm{CB}_{40}$ respectively and samples with contaminants had fuel consumption rate which was $11.2 \%, 15.84 \%$ and $23.77 \%$ higher for $\mathrm{CB}_{10}, \mathrm{CB}_{20}$ and $\mathrm{CB}_{40}$ respectively when compared to diesel.

- As evident from the given data metal contaminant may have a further poor negative impact however it wasn't as much significant. However the $\mathrm{NO}_{\mathrm{x}}$ emissions for biodiesel was significantly higher than diesel as validated from several research papers [21, 22].

\subsection{2 $\mathrm{CO}_{2}$ and $\mathrm{CO}$ emission}

Figures 9 and 10 illustrates the variation of $\mathrm{CO}_{2}$ and $\mathrm{CO}$ values as compared with the load applied respectively. $\mathrm{A}$ generic decreasing curve was observed for $\mathrm{CO}$ which indicated the decrease in CO levels with the increase in loads as with increase in load engine runs on lean mixture which gives sufficient oxygen for combustion of $\mathrm{CO}$ as validated by Aydin et al. [23]. On the other hand an increasing trend was observed for $\mathrm{CO}_{2}$ which can be due to decrease in levels of $\mathrm{CO}$ and proper combustion of fuel. Also, $\mathrm{CO}$ and $\mathrm{CO}_{2}$ value may get slightly higher as compared to pure biodiesel without additives because of disturbance of addition of antioxidants and additives [23]. The variation in values observed for $10 \mathrm{~kg}$ are stated as follows:

- Samples without contaminant had $\mathrm{CO}$ emission which was $0 \%, 50 \%, 0 \%$ lower for $\mathrm{CB}_{10}, \mathrm{CB}_{20}$ and $\mathrm{CB}_{40}$ respectively and samples with contaminants had fuel consumption rate which was $0 \%$ higher for all $\mathrm{CB}_{10}, \mathrm{CB}_{20}$ and $\mathrm{CB}_{40}$ when compared to diesel indicating its impact to be minimal.

- Samples without contaminant had $\mathrm{CO}_{2}$ emission which was $32.09 \%, 38.27 \%, 22.8 \%$ lower for $\mathrm{CB}_{10}, \mathrm{CB}_{20}$ and $\mathrm{CB}_{40}$ respectively and samples with contaminants had fuel consumption rate which was $44.44 \%, 41.35 \%$ and $35.18 \%$ lower for $\mathrm{CB}_{10}, \mathrm{CB}_{20}$ and $\mathrm{CB}_{40}$ respectively when compared to diesel.

- As evident from the given data additives had a significant impact on the emissions of $\mathrm{CO} 2$ as with the reduction of $\mathrm{CO}$ value of $\mathrm{CO} 2$ increases which is hence controlled by additives in biodiesel.

\section{Conclusion}

The current experimental research deals with the varying concentrations of antioxidant, pyrogallol and metal contaminant concentration which is aluminium powder and provides the insight to the optimization of the fuel properties (viscosity and flash point) of the biodiesel with the appropriate concentration of the same. Issues aroused due to the addition of antioxidants into the biodiesel were addressed as they increase the viscosity of the fluid resulting in degradation from the level of consumption on the contrary it prevents the fluid from getting oxidized. Cottonseed biodiesel contains very high level of unsaturation and is highly susceptible to oxidization over the given period of time.

- Most optimum results for the viscosity of cottonseed oil biodiesel were obtained with aluminium concentration as $35 \mathrm{ppm}$ and pyrogallol concentration $90 \mathrm{ppm}$ and 23 days.

- Viscosity's optimum value was found to be 5.34 centistokes at the end of 23 days with the concentrations of metal contaminants and antioxidant as stated above. Viscosity of biodiesel was highly reduced with the addition of antioxidant. Optimum results were obtained with help of design experiment software and the best result was chosen from the list of 100 solutions.

- Engine performance was found to be lower in biodiesel. It was due to the governing the poor spray charac- 
teristics and high viscosity of biodiesel. Addition of anti-oxidant certainly made the performance better by reducing the viscosity however addition of metal contaminants acted adversely giving results of lower performance than anti-oxidant mixed samples.

- Brake thermal Efficiency was found best for diesel as the fuel consumption rate of the diesel was lowest. Biodiesel samples mixed with anti-oxidant showed brake thermal efficiency less than diesel however still comparable in low percentage blends as the addition of additives worked positively.

- It was also found that the $\mathrm{NO}_{\mathrm{x}}$ emission is relatively higher for the contaminated biodiesel as compared to biodiesel with only antioxidant. Use of antioxidant inhibited the formation of $\mathrm{NO}_{\mathrm{x}}$ to a significant value. $\mathrm{NO}_{x}$ emission was certainly larger than diesel.

- $\mathrm{CO}_{2}$ or $\mathrm{CO}$ emission for contaminates were lower but the $\%$ decrease was very less so it can be concluded that with the increase in metal concentration there is an increase in emission. CO emission was decreased as biodiesel is a oxygen rich fuel hence proper reaction takes place with $\mathrm{CO} . \mathrm{CO}_{2}$ emissions were found to be decreased as compared to diesel engine however, addition of antioxidant in biodiesel resulted in a slight increase in $\mathrm{CO}_{2}$ values due to disturbances in addition of additives in the sample.

- Metal contaminants had no significant effect in the values of $\mathrm{CO}$ and $\mathrm{CO}_{2}$ as the emission values increased however the change was negligible.

\section{Compliance with ethical standards}

Conflict of interest On behalf of all authors, the corresponding author states that there is no conflict of interest.

\section{References}

1. Jain S, Sharma MP (2010) Stability of biodiesel and its blends: a review. Renew Sustain Energy Rev 14(2):667-678

2. Sarin R, Sharma M, Sinharay S, Malhotra RK (2007) Jatropha-palm biodiesel blends: an optimum mix for Asia. Fuel 86(10-11):1365-1371

3. Knothe G (2005) Dependence of biodiesel fuel properties on the structure of fatty acid alkyl esters. Fuel Process Technol 86(10):1059-1070

4. An H, Yang WM, Maghbouli A, Li J, Chou SK, Chua KJ (2013) Performance, combustion and emission characteristics of biodiesel derived from waste cooking oils. Appl Energy 112:493-499

5. Fernandes DM, Sousa RM, de Oliveira A, Morais SA, Richter EM, Muñoz RA (2015) Moringa oleifera: a potential source for production of biodiesel and antioxidant additives. Fuel 146:75-80
6. Pantoja SS, da Conceição LRV, da Costa CE, Zamian JR, da Rocha Filho GN (2013) Oxidative stability of biodiesels produced from vegetable oils having different degrees of unsaturation. Energy Convers Manag 74:293-298

7. Chhabra M, Saini BS, Dwivedi G (2019) Impact assessment of biofuel from waste neem oil. Energy Sour A Recov Util Environ Eff 6(1):1-12

8. Jain S, Sharma MP (2013) Effect of metal contaminants and antioxidants on the storage stability of Jatropha curcas biodiesel. Fuel 109:379-383

9. Dwivedi G, Sharma MP (2014) Impact of antioxidant and metals on biodiesel stability - a review. J Mater Environ Sci 5(5):1412-1425

10. Osawa WO, Sahoo PK, Onyari JM, Mulaa FJ (2016) Effects of antioxidants on oxidation and storage stability of Croton megalocarpus biodiesel. Int J Energy Environ Eng 7(1):85-91

11. Schober S, Mittelbach M (2004) The impact of antioxidants on biodiesel oxidation stability. Eur J Lipid Sci Technol 106(6):382-389

12. Serrano M, Bouaid A, Martínez M, Aracil J (2013) Oxidation stability of biodiesel from different feedstocks: influence of commercial additives and purification step. Fuel 113:50-58

13. Varatharajan K, Pushparani DS (2018) Screening of antioxidant additives for biodiesel fuels. Renew Sustain Energy Rev 82:2017-2028

14. Focke WW, Van der Westhuizen I, Grobler AL, Nshoane KT, Reddy JK, Luyt AS (2012) The effect of synthetic antioxidants on the oxidative stability of biodiesel. Fuel 94:227-233

15. Avase SA, Srivastava S, Vishal K, Ashok HV, Varghese G (2015) Effect of pyrogallol as an antioxidant on the performance and emission characteristics of biodiesel derived from waste cooking oil. Procedia Earth Planet Sci 11:437-444

16. Ramalingam S, Rajendran S, Ganesan P, Govindasamy M (2018) Effect of operating parameters and antioxidant additives with biodiesels to improve the performance and reducing the emissions in a compression ignition engine-a review. Renew Sustain Energy Rev 81:775-788

17. Celik M, Yucesu SH, Guru M (2016) Investigation of the effects of organic based manganese addition to biodiesel on combustion and exhaust emissions. Fuel Process Technol 152(152):83-92

18. Celik M, Solmaz H, Yucesu SH (2015) Examination of the effects of organic based manganese fuel additive on combustion and engine performance. Fuel Process Technol 139:100-107

19. Fazal MA, Jakeria MR, Haseeb ASMA, Rubaiee S (2017) Effect of antioxidants on the stability and corrosiveness of palm biodiesel upon exposure of different metals. Energy 135:220-226

20. Sarin A, Arora R, Singh NP, Sarin R, Malhotra RK (2010) Oxidation stability of palm methyl ester: effect of metal contaminants and antioxidants. Energy Fuels 24(4):2652-2656

21. Akhabue CE, Iworah JC, Aisien FA (2014) Effect of selected metal contaminants on the stability of castor oil methyl ester. J Fuels. https://doi.org/10.1155/2014/641849

22. Nabi MN, Rahman MM, Akhter MS (2009) Biodiesel from cotton seed oil and its effect on engine performance and exhaust emissions. Appl Therm Eng 29(11-12):2265-2270

23. Aydin H, Bayindir H (2010) Performance and emission analysis of cottonseed oil methyl ester in a diesel engine. Renew Energy 35(3):588-592

24. Fan X, Wang X, Chen F, Geller DP, Wan PJ (2008) Engine performance test of cottonseed oil biodiesel. Open Fuels Energy Sci J 1(7):40-45

25. Rakopoulos CD, Rakopoulos DC, Hountalas DT, Giakoumis EG, Andritsakis EC (2008) Performance and emissions of bus engine using blends of diesel fuel with bio-diesel of sunflower or cottonseed oils derived from Greek feedstock. Fuel 87(2):147-157 
26. Yücesu HS, Illkiliç C (2006) Effect of cotton seed oil methyl ester on the performance and exhaust emission of a diesel engine. Energy Sour A 28(4):389-398

27. Kumara AS, Maheswarb D, Reddyc KVK (2009) Comparision of diesel engine performance and emissions from neat and transesterified cotton seed oil. Jordan J Mech Ind Eng 3:190-197

28. Celik M (2017) Examining combustion and emission characteristics of cotton methyl ester to which manganese additive material was added. J Mech Sci Technol 31(12):6041-6050

29. Celik M (2016) Combustion performance and exhaust emission characteristics of organic based manganese addition to cotton methyl ester. Appl Therm Eng 108:1178-1189

30. Rashed MM, Kalam MA, Masjuki HH, Rashedul HK, Ashraful AM, Shancita I, Ruhul AM (2015) Stability of biodiesel, its improvement and the effect of antioxidant treated blends on engine performance and emission. RSC Adv 5(46):36240-36261

31. Hasni K, Ilham Z, Dharma S, Varman M (2017) Optimization of biodiesel production from Brucea javanica seeds oil as novel non-edible feedstock using response surface methodology. Energy Convers Manag 149:392-400
32. de Sousa LS, Garcia MAS, Santos ECP, do Nascimento Silva J, de Castro AG, de Moura CVR, de Moura EM (2019) Study of the kinetic and thermodynamic parameters of the oxidative degradation process of biodiesel by the action of antioxidants using the Rancimat and PetroOXY methods. Fuel 238:198-207

33. Balaji G, Cheralathan M (2014) Experimental investigation to reduce emissions of $\mathrm{Cl}$ (compression ignition) engine fuelled with methyl ester of cottonseed oil using antioxidant. Int J Ambient Energy 35(1):13-19

34. Rashedul HK, Masjuki HH, Kalam MA, Ashraful AM, Rahman SA, Shahir SA (2014) The effect of additives on properties, performance and emission of biodiesel fuelled compression ignition engine. Energy Convers Manag 88:348-364

35. Murali Krishna B, Mallikarjuna JM (2009) Properties and performance of cotton seed oil-diesel blends as a fuel for compression ignition engines. J Renew Sustain Energy 1(2):023106

Publisher's Note Springer Nature remains neutral with regard to jurisdictional claims in published maps and institutional affiliations. 